\title{
SALA DE AULA INVERTIDA APOIADA PELA GESTÃO DO CONHECIMENTO
}

\author{
Daniela Fiorini, PPGGCO/Unicesumar, danibissolifiorini@gmail.com \\ Iara Carnevale de Almeida, PPGGCO/Unicesumar, \\ iara.almeida@unicesumar.edu.br \\ Letícia Fleig Dal Forno, PPGGCO/Unicesumar, lefleig@gmail.com \\ Marlise Geller, PPGECIM/ULBRA, marlise.geller@ulbra.br
}

\begin{abstract}
RESUMO: O distanciamento social imposto pelo Covid-19 fez com que as instituições de ensino passassem por um processo de ressignificação nos processos pedagógicos. Este estudo refina um planejamento de aulas baseado na Sala de Aula Invertida com Aprendizagem Baseada em Problemas e Orientação por meio de Projetos. Neste planejamento têm-se também práticas e ferramentas da Gestão do Conhecimento (GC) que podem ser vistas como estratégias que permitem, por exemplo, captar, estruturar e mapear conhecimentos como reutilizar conhecimento já estruturado. As adaptações feitas nesse planejamento permitem que ocorram momentos "antes" e "depois" das aulas remotas online. A metodologia adotada contempla pesquisa aplicada com abordagem qualitativa através de pesquisa descritiva de estudo de caso, após pesquisa bibliográfica exploratória e documental. Observou-se maior envolvimento, por parte dos alunos, para exporem os seus trabalhos e/ou dúvidas nas aulas remotas online. Isto proporcionou que as aulas fossem mais interessantes e participativas, o professor pode dar feedback sobre os trabalhos fazendo com que a "dúvida, erro ou acerto de um aluno" pudesse ser esclarecida e compreendida por todos. Espera-se com este estudo contribuir com as estratégias para promover a aprendizagem em períodos de isolamento social similares ao ocorrido com Covid-19.
\end{abstract}

Palavras chave: Planejamento de aulas com metodologias ativas. Estudo de caso. Práticas e ferramentas da Gestão do Conhecimento. Sala de aula invertida.

\section{FLIPPED CLASSROOM SUPPORTED BY KNOWLEDGE MANAGEMENT}

ABSTRACT: Educational institutions went through a process of reframing in the pedagogical processes social distance imposed by Covid-19. This study refines a lesson plan based on the Inverted Classroom with Problem-Based Learning and Project Orientation. This planning presents Knowledge Management practices and tools as strategies to allow, for example, to capture, structure, map knowledge and how to reuse knowledge, already structured. The adaptations of this planning allow for "before" and "after" moments of remote online classes. The methodology adopted includes applied research with a qualitative approach through descriptive case study research, with exploratory and documentary bibliographic research. There is much more involvement on the part of students to expose their work and/or doubts in remote online classes. This provided that the classes were more interesting, the teacher can give feedback on the work making the "doubt, mistake or right of a student" to be clarified and understood by everyone. We hope, in this study, to contribute with strategies to promote learning in periods of social isolation similar to what happened with Covid-19. 
Keywords: Class planning with active methodologies. Case study. Knowledge Management practices and tools. Flipped classroom.

\section{INTRODUÇÃO}

A pandemia do novo coronavírus (Covid-19) trouxe para o Brasil, como para todo o mundo, o desafio de adotar medidas de distanciamento social de forma a garantir o controle da disseminação deste vírus. Na educação houve uma forma rápida de aplicar essas medidas: o fechamento das escolas. Foram interrompidas as aulas presenciais e, portanto, respeitado o distanciamento social. Segundo a Unesco (2020), 91,4\% da população de estudantes no mundo foram afetados pelo fechamento das escolas, o que reflete 1,57 bilhão de estudantes fora da sala de aula presencial.

Diante desse novo cenário na educação, o esforço das escolas, e dos professores, têm sido buscar formas de transferir as aulas presenciais para um formato de ensino remoto, no qual os alunos possam continuar seus estudos em suas residências com apoio de recursos tecnológicos. No entanto, é importante destacar que o ensino remoto não é sinônimo de aula a distância. Há diferentes maneiras de estimular a aprendizagem remota que, se bem estruturadas, permitem que haja atividades educacionais que podem cumprir mais do que uma função puramente acadêmica. Contudo, existe a necessidade de que os professores tenham atenção aos seus planejamentos de aulas. Este planejamento deve permitir que os alunos, acostumados com uma rotina de aulas presenciais, continuem a ter uma vivência efetiva neste novo processo de ensino-aprendizagem de aulas remotas.

Behrens (2015) defende que para aprendizagem efetiva dos alunos é preciso adotar processos pedagógicos que permitam discutir/problematizar a realidade vivenciada pelos alunos, que permitam fortalecer a formação deste aluno enquanto profissional, possibilitando reflexão e proporcionando maior criatividade e criticidade por parte desses alunos. Importante ressaltar que Marin et al. (2010) já apresentava propostas que permitiam aplicação de metodologias ativas, tais como: aprendizagem entre pares, discussões em grupo, estudos de caso, sala de aula invertida, aprendizagem colaborativa, aprendizagem baseada em problemas, aprendizagem baseada em equipe, ensino baseado em projeto, entre outros.

Bergmann e Sams (2016) definem a Sala de Aula Invertida como sendo uma metodologia que propõe a inversão do modelo de ensino tradicional, proporcionando aulas menos expositivas, porém mais produtivas, colaborativas e participativas. Diversos outros autores apontam definições e características para a Sala de Aula Invertida, destacando-se os estudos de Strayer (2007), Munhoz (2015), Honório (2016), Suhr (2016). Considerando estas ideias, diferente do modelo tradicional de ensino, a proposta de sala de aula invertida pretende maior envolvimento e autonomia dos alunos, onde estes têm o compromisso de assistir aos vídeos e fazer perguntas adequadas, podendo recorrer ao professor para melhor compreensão dos conceitos apresentados.

Além disso, as propostas de Aprendizagem Baseada em Problemas (em inglês, Problem Based Learning - PBL) e Orientação por meio de Projetos (OMP) podem vir a apoiar o planejamento das aulas em um modelo de Sala de Aula Invertida. A PBL é uma proposta metodológica, que pode ser encontrada em diversos contextos do sistema educacional, que vão desde a Educação Básica à Educação Superior. A Aprendizagem Baseada em Problemas fundamenta-se em problemas reais e pretende que, em pequenos grupos, os alunos pesquisem e discutam o problema apresentado para encontrarem uma solução, garantindo assim a compreensão e a aquisição do conhecimento e diferentes estudos inferem sobre como a PBL pode possibilitar a aprendizagem colaborativa, valorizando conhecimentos prévios, reflexões e o posicionamento sobre o problema 
apresentado (RIBEIRO, 2010; ALARCÃO; TAVARES, 2013; FARIAS; MARTINS; CRIST, 2015; GOMES; BRITO; VARELA, 2016);

Relativamente à OMP, infere-se que a OMP busca ajudar o aluno a obter informações, ler, conversar, anotar dados, calcular, juntando o necessário para iniciar seu próprio projeto, contemplando importantes avanços na questão do conhecimento acerca da aprendizagem, possibilitando o desenvolvimento da responsabilidade e autonomia dos alunos, a autenticidade do projeto, o envolvimento de complexidade e resolução de problemas. Destaca-se ainda que a produção do aluno surge de problemas capazes de impulsionar a contextualização de conceitos já conhecidos por ele e na promoção de outros problemas (BORDENAVE; PEREIRA, 1982; BLUMENFELD et al., 1991; ABRANTES, 1995; PRADO, 2003; VILARINHO, 2004; MORAN, 2015; VALENTE; ALMEIDA; GERALDINE, 2017).

Prado (2005) destaca a proposta da OMP como um meio de se instaurar mudanças imprescindíveis nas salas de aula, em especial as da Educação Superior. Ribeiro e Oliveira (2017) destacam que o grande valor de trabalhar com projetos está em utilizálos como uma ferramenta pedagógica e metodológica, capaz de desenvolver o espírito crítico e investigativo do aluno, permitindo que ocorram novas descobertas e uma melhor interação entre os alunos e professor por meio da resolução de situações-problema.

Conforme Batista (2004), as práticas e ferramentas da GC podem ser compreendidas como sendo estratégias de implementação que permitem tanto captar, quanto reutilizar conhecimento estruturado; captar e compartilhar lições aprendidas com a prática; identificar fontes e redes de expertise; estruturar e mapear conhecimentos necessários para aumentar o desenho; mediar e controlar o valor econômico do conhecimento; e sintetizar e compartilhar advindo de fontes externas.

Portanto, esse artigo propõe um refinamento da proposta pedagógica de sala de aula invertida aplicando Aprendizagem Baseada em Problemas (PBL) e Orientação por meio de Projetos (OMP) com práticas e ferramentas de GC, proposta por Fiorini (2019), de forma que esta proposta possa ser aplicada no ensino remoto.

\section{PLANEJAMENTO DE AULAS REMOTAS}

Para compreensão do planejamento de aulas proposto, o Quadro 1 apresenta as práticas da GC, segundo o manual da Asian Productivity Organization (APO, 2009), utilizadas no planejamento das aulas e, na sequência, o Quadro 2 salienta as etapas do ciclo da Gestão do Conhecimento que ocorrem com a aplicação dessas práticas.

Quadro 1 - As práticas da Gestão do Conhecimento

Sistema de Gerenciamento de Documentos - Forma eficiente e eficaz de acesso a documentos para evitar sobrecarga de informações. Fundamental para encontrar a informação correta no tempo certo. Brainstorming - Prática utilizada para auxiliar a equipe na geração de ideias e inovação. O processo é dividido em duas fases: divergente e convergente. Na fase divergente, a equipe gera insights, adiando o julgamento sobre as ideias para depois, na segunda fase, decidir e selecionar as melhores ideias. Ferramentas de Busca Avançada - Motor de busca para melhoria significativa nos resultados de pesquisas. Formas para obter a informação certa e diminuir a sobrecarga de informações. Narrativas Prática utilizada para compartilhar experiências e lições aprendidas, por meio de relatos e eventos que consistem em, literalmente, contar histórias de forma simples, utilizando palavras e imagens. Espaço Virtual Colaborativo - Prática que permite que as pessoas trabalhem em colaboração, compartilhando documentos, edição colaborativa em coautoria, áudio e videoconferência, independentemente de onde estejam localizadas fisicamente. Espaço de Rede Social - Grupo de pessoas que compartilham uma área de interesse comum. São sistemas de apoio social on-line para encontrar pessoas com necessidades e interesses em comum, compartilhar conteúdos e documentos relevantes. Blog - Diário que contém uma lista de entradas, geralmente no sentido inverso à ordem cronológica. As entradas são artigos curtos ou 
histórias relativas a eventos da atualidade. Fórum de Discussão - Prática utilizada para discutir e compartilhar informações, ideias e experiências que contribuirão para o desenvolvimento de competências e aperfeiçoamento de processos e atividades da organização.

Revisão de Aprendizagem - Prática utilizada pela equipe de projeto para auxiliar na aprendizagem do processo de trabalho. O objetivo é que os membros da equipe possam aprender continuamente durante $o$ projeto.

Fonte: Adaptado de Fiorini (2019)

Quadro 2 - As práticas e o ciclo da Gestão do Conhecimento

\begin{tabular}{|l|c|c|c|c|c|}
\hline \multicolumn{1}{|c|}{ PRÁTICA DE GC } & IDE & CRI & ARM & COM & APLI \\
\hline Sistema de Gerenciamento de Documentos & & & $\mathrm{X}$ & $\mathrm{X}$ & $\mathrm{X}$ \\
\hline Brainstorming & & $\mathrm{X}$ & & & \\
\hline Ferramentas de Busca Avançada & $\mathrm{X}$ & $\mathrm{X}$ & & & $\mathrm{X}$ \\
\hline Narrativas & & & & $\mathrm{X}$ & \\
\hline Espaço Virtual Colaborativo & $\mathrm{X}$ & $\mathrm{X}$ & $\mathrm{X}$ & $\mathrm{X}$ & $\mathrm{X}$ \\
\hline Espaço de Rede Social & & & & $\mathrm{X}$ & \\
\hline Blog & & $\mathrm{X}$ & $\mathrm{X}$ & $\mathrm{X}$ & $\mathrm{X}$ \\
\hline Fórum de Discussão & & & & $\mathrm{X}$ & \\
\hline Revisão de Aprendizagem & & $\mathrm{X}$ & $\mathrm{X}$ & $\mathrm{X}$ & \\
\hline
\end{tabular}

Legenda: IDE - identificação; CRI - criação; ARM - armazenamento; COM - compartilhamento; APLI aplicação.

Fonte: Adaptado de Fiorini (2019)

Observando as características apresentadas nos Quadros 1 e 2, é possível compreender que as práticas de GC são ações dinâmicas que devem promover um fluxo de compartilhamento do conhecimento, bem como um fluxo de disseminação do conhecimento para a promoção da reutilização ou atualização do conhecimento. Tais práticas, estando alinhadas à produção, retenção, disseminação, compartilhamento e aplicação do conhecimento, incluindo pessoas, sistemas, tecnologias e conhecimentos, apresentam como objetivo o melhorar o desempenho individual e do grupo nas organizações.

O reconhecimento das práticas de GC repercute também na compreensão de que as relações estabelecidas em uma organização se referem à integração entre três fatores Pessoas, Processos e Tecnologia - que resultam em um fluxo de ações dinâmicas que perpassam a avaliação, a contextualização e a atualização, conforme representado por Davila et al. (2015). De forma semelhante, observa-se esta relação estabelecida entre pessoas, processos e tecnologias na sala de aula invertida, através do envolvimento dos Professores e Alunos (Pessoas) que desenvolvem e aplicam estratégias de ensino (Processos), com o emprego de práticas e ferramentas da GC (Tecnologia), conforme apresentado na Figura 1. 


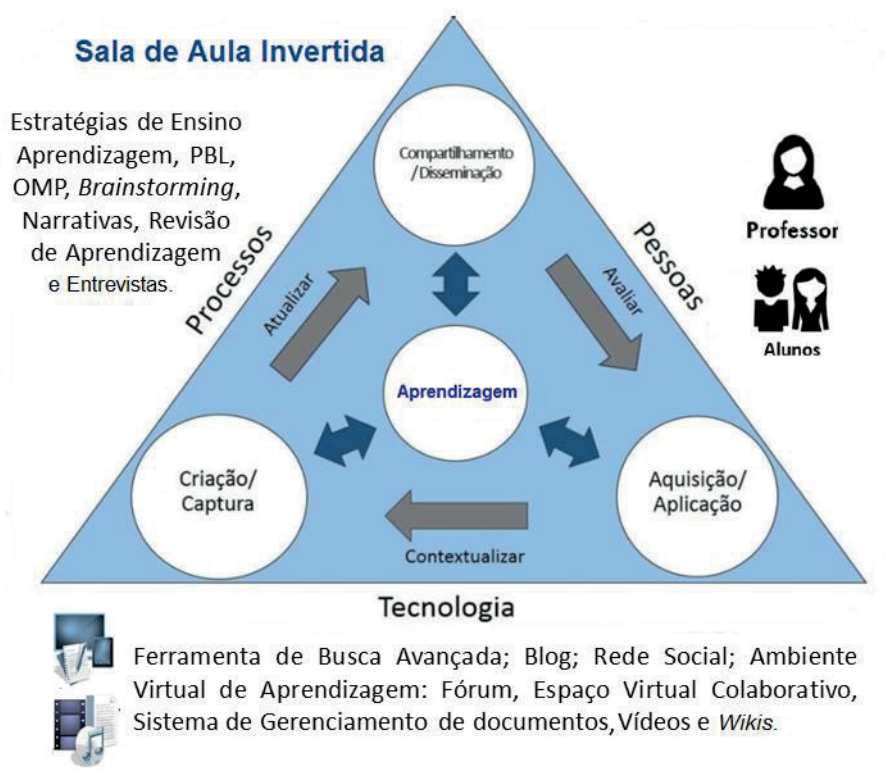

Figura 1 - Pessoas, Processos e Recursos Tecnológicos da GC em uma Sala de Aula Invertida Fonte: (FIORINI, 2019, p.113)

A proposta metodológica da Sala de Aula Invertida indica que haja três momentos, denominados de "antes", "durante" e "depois". Porém esta proposta não especifica estratégias e nem recursos que podem ser utilizados nos três momentos. As práticas acima apresentadas permitem sanar esta lacuna da Sala de Aula Invertida. Além disto, a escolha da prática da GC deverá ter sempre em atenção na ocorrência (parcial ou total) do ciclo da GC. A seguir, o Quadro 3 refina a proposta de planejamento pedagógico de (FIORINI, 2019), onde foram aplicadas estratégias de PBL e OMP com previsão de aulas nas modalidades a distância ou presenciais.

Quadro 3 - Planejamento das aulas

Durante a primeira aula remota o professor/pesquisador deve apresentar à turma de alunos a proposta da Sala de Aula Invertida, informando-os sobre o objetivo da proposta, assim como sobre todas as etapas a serem vivenciadas nas aulas seguintes, trazendo uma breve capacitação sobre os recursos tecnológicos a serem utilizados nas próximas aulas. Previamente à segunda aula o professor deve selecionar os conteúdos, separar vídeos e artigos sobre o tema da aula, que durante a aula serão compartilhados com os alunos para que estes acessem através do SGD, para realizarem leitura dos artigos e visualizarem os vídeos. Na terceira aula remota será realizada a prática do Brainstorming. Sugere-se o uso de uma ferramenta que permita gerar uma nuvem de palavras. Após, realizar uma discussão geral com fechamento das ideias. Para a quarta aula serão utilizadas ferramentas de busca avançada e apresentação de narrativas. Para isso, o professor deve disponibilizar informações sobre ferramentas de busca avançada para os alunos e estes devem realizar pesquisa a respeito de possibilidades, exemplos e soluções sobre as temáticas discutidas em sala de aula. Como produto final, os alunos devem produzir narrativas, de forma individual, sobre as soluções encontradas/estudadas, e as enviarão para o professor, utilizando de ferramentas de compartilhamento, à escolha do professor (e-mail, ambiente virtual de aprendizagem, SGD). Durante a quinta aula, será utilizado o Espaço Virtual Colaborativo para a construção de um projeto. Os alunos poderão utilizar as orientações disponibilizadas pelo professor e irão começar em grupo a criação de projeto. Durante a sexta aula, os alunos continuam a criação de projeto, utilizandose de Espaço Virtual Colaborativo. Após a aula os alunos publicam em Espaço de Rede Social as primeiras etapas de seus projetos. Na sétima aula remota, os projetos serão apresentados por meio de narrativas, utilizando-se de recursos de videoconferência que permitam compartilhamento de tela. Nesta atividade há a interação entre alunos e professor, gerando reflexões e conhecimento. Após a oitava aula, os alunos deverão publicar os seus projetos, apresentados na aula anterior, em ambiente criado pelo professor (por exemplo um Blog), que permita a integração entre os alunos e formalização de opiniões desses alunos sobre os projetos dos colegas, por meio de fórum de discussão. Para finalizar, antes da nona aula, o professor deve extrair das publicações do Blog as ideias centrais postadas pelos alunos. 
Durante a nona aula, essas palavras são colocadas em posse dos alunos, esses por sua vez devem criar o mapa conceitual no quadro, finalizando com uma breve discussão sobre o mapa conceitual criado.

Fonte: Adaptado de Fiorini (2019)

Salientamos que, para o Brainstorming, propomos que o professor inicie com um "aquecimento", conversando informalmente sobre assuntos relacionados à temática da aula. Em seguida, deve lançar algumas problemáticas sobre o assunto da aula, com base nos materiais estudados em casa pelos alunos. Posteriormente, o professor explica a prática do brainstorming aos alunos indicando que os mesmos devem se organizar em pequenos grupos, recebendo pequenas frases/problemas sobre o assunto da aula. Aqui é importante usar uma ferramenta que possibilite, de forma rápida, a formação de grupos onde o professor possa acompanhar a discussão. A tarefa a ser executada é simples: os alunos devem discutir sobre essa frase/problema e indicar, individualmente, palavras que eles acreditam que se relacionam com o tema estudado. Estas palavras devem ser organizadas para que um dos membros apresente a ideia ao grupo restante da turma, onde a frase será posteriormente postada para o grande grupo.

\section{METODOLOGIA}

A metodologia desta pesquisa foi aplicada com abordagem qualitativa, realizando-se pesquisa bibliográfica exploratória e pesquisa descritiva, na perspectiva de um estudo de caso (GERHARDT; SILVEIRA, 2009; VENTURA, 2007). Nesta pesquisa, o estudo de caso foi realizado em uma disciplina de um curso de graduação na modalidade presencial de Engenharia de Software em uma IES da região Metropolitana de Maringá, Paraná, envolvendo 84 alunos e 1 professor. A coleta de dados foi realizada por meio de estudo documental do registro das aulas remotas, com análise de conteúdo realizada a partir de registros escritos do professor, inspirado em Bardin (2002). Esses registros do professor serviram para verificar a dificuldade e/ou facilidade do professor em seguir o planejamento, ao detectar diferenciações de aceitação e participação dos alunos nas aulas aplicadas, considerando as especificidades da formação acadêmica dos alunos. A Figura 2 apresenta o planejamento proposto no Quadro 3, indicando como ocorre o ciclo de GC nos diferentes momentos das aulas remotas. 


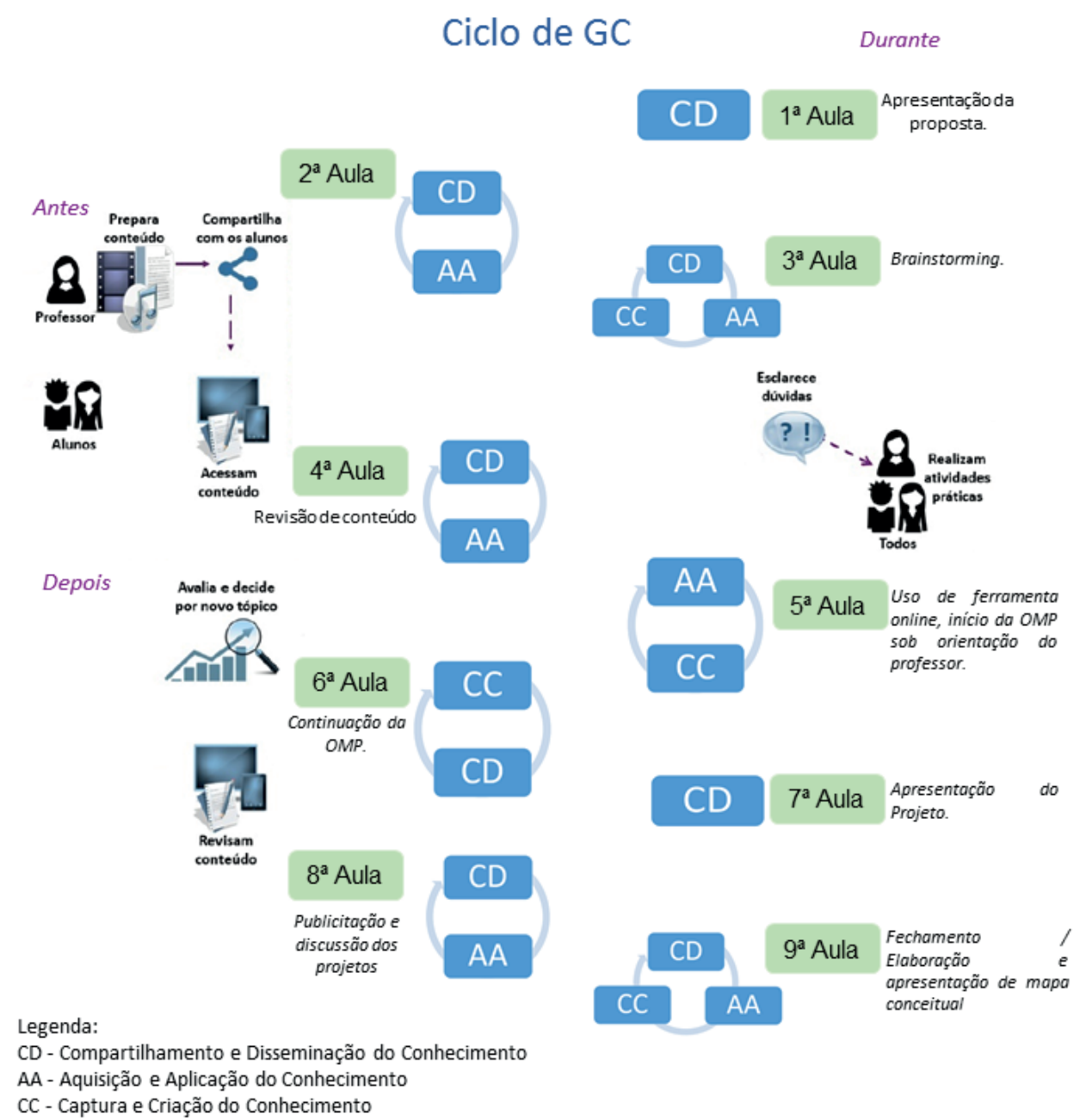

Figura 2 - Planejamento das Aulas Remotas e o Ciclo da GC Fonte: adaptado de (FIORINI, 2019, p.112)

Note que as aulas 1, 3, 5, 7 e 9 são as aulas remotas online, onde o professor interage com os alunos; as aulas 2 e 4 são os momentos previstos que o aluno/professor devem preparar antes das aulas remotas online; e as aulas 6 e 8 são os momentos previstos com atividades que devem ser realizadas depois das aulas remotas online.

\section{RESULTADOS E DISCUSSÃO}

Foi possível aplicar a sequência de aulas elaborada em Fiorini (2019). No entanto, foi necessário realizar adaptações para as aulas propostas como presenciais, de forma que estas passassem a ser aulas remotas com momentos "antes e durante" as aulas remotas. Importante destacar que as estratégias PBL e OMP tiveram sequência similar ao planejado na sequência de aulas, no que se refere ao levantamento do problema (PBL) e a execução de projeto para solucionar o problema (OMP). Acredita-se que a formação profissional e acadêmica da área de Exatas possa ter possibilitado maior esquematização das ações, assim como constava na sequência inicial das aulas. Outro fato importante a destacar, na aplicação das aulas no curso de Engenharia de Software, foi a familiaridade dos alunos com os recursos tecnológicos, que permitiu a utilização com maior domínio das ferramentas com tecnologia de informação e comunicação, o que serviu ainda como forma de atrativo aos alunos. 
Além disto, para a concretização do planejamento das aulas, o professor precisou pensar sobre a sequência de aulas oferecida sob uma ótica de entendimento da Sala de Aula Invertida, sobre sua elaboração e a importância no processo ensino-aprendizagem e na formação de seus alunos, assim como na articulação conteúdo/metodologia no desenvolvimento da prática pedagógica. Com isso, foi possível que o professor pensasse em novas ações a serem agregadas na sequência inicial das aulas, desencadeando ações que oportunizaram reflexão sobre a prática do planejamento.

Pode-se inferir que as aulas remotas online proporcionaram momentos aos quais os alunos apresentavam os seus trabalhos para o professor e demais colegas de forma. Observou-se maior envolvimento e interação por parte dos alunos, em exporem seus trabalhos, dúvidas e comentários o que proporcionou que as aulas fossem mais interessantes e participativas, principalmente no que se refere ao feedback do professor sobre as tarefas desenvolvidas, fazendo com que a "dúvida, erro ou acerto de um aluno" pudesse ser esclarecida para todos os alunos.

\section{CONCLUSÕES}

Percebe-se a importância do problematizar nas aulas iniciais de forma que haja reconhecimento e compreensão por parte dos alunos sobre o que se pretende na proposta das aulas seguintes com momentos "antes" e "depois", além da importância de haver participação efetiva destes nas aulas remotas online. Além disso, é necessário promover meios para que o aluno desenvolva competências e habilidades para construir sua própria aprendizagem. Ou seja, é necessário ter tempo para o aluno se familiarizar com as estratégias da Sala de Aula Invertida, entendendo seu papel ativo nesse tipo de metodologia, cabendo a ele maior dedicação nos diferentes momentos, significando que este deve ter tempo de estudo em casa, organização com disciplina - que são individuais e da concepção de cada aluno. Assim como também se faz necessário que o professor possa intervir junto aos seus alunos, no decorrer das aulas remotas online, incentivandoos nas discussões e fomentando a trocas de ideias. Finalmente, esta proposta de aulas remotas pretende contribuir com estratégias para manter a aprendizagem em períodos de isolamento social similares ao ocorrido com Covid-19.

\section{REFERÊNCIAS BIBLIOGRÁFICAS}

ABRANTES, P. Trabalho de projetos e aprendizagem da matemática. In: ABRANTES, P. Avaliação e Educação Matemática. Rio de Janeiro: MEM/USU - GEPEM, 1995. 87p. (Série Reflexões em Educação Matemática).

ALARCÃO, I.; TAVARES, J. Supervisão da prática pedagógica. Coimbra: Edições Almedina, 2013.

BARDIN, L. Análise de conteúdo. Lisboa: Edições 70, 2002.

BATISTA, F. Governo que aprende: Gestão do Conhecimento em Organizações do Executivo Federal, 2004. Disponível em: http://189.21.130.177/portal/pls/portal/docs/2056692.PDF. Acesso em: 19 nov. 2017.

BATISTA; R. S.; BATISTA, R. Os anéis da serpente: a aprendizagem baseada em problemas e as sociedades de controle. Ciênc. Saúde coletiva, Rio de Janeiro, v. 14, n. 4, p. 1183-1192, ago. 2009. Disponível em: 
http:/www.scielo.br/scielo.php?script=sci arttext\&pid=S1413$\underline{81232009000400024 \& \operatorname{lng}=\text { en\&nrm=iso. }}$.

BERGMANN, J.; SAMS, A. Sala de aula invertida: uma metodologia ativa de aprendizagem. Rio de Janeiro: LTC, 2016.

BEHRENS, M. A. Paradigma da complexidade na prática pedagógica dos professores universitários: inovações epistemológicas e tecnológicas para ensinar e para aprender. In: CAVALCANTE, M. M. D. (org.). et al. Didática e a prática de ensino: diálogos sobre a escola, a formação de professores e a sociedade. Fortaleza, CE: EdUECE, 2015. Disponível em:

http://www.uece.br/endipe2014/ebooks/livro4/creditos livro04.pdf. Acesso em: 10 abr. 2018.

BLUMENFELD et al. Creating usable innovations in systemics reform: scaling-up technology-embebed project-based Science in urbe schools. Educational Psychologist Blumenfeld, 1991.

BORDENAVE, J.D.; PEREIRA, A.M. Estratégias de ensino-aprendizagem. Petrópolis, RJ: Vozes, 1982.

FARIAS, P.A.M. de; MARTINS, A.L.A.R.; CRISTO, C.S. Aprendizagem Ativa na Educação em Saúde: Percurso Histórico e Aplicações. Revista Brasileira de Educação Médica, Rio de janeiro, v. 39, n. 1, jan./mar. 2015.

FIORINI, D. B. A sala de aula invertida e práticas de gestão do conhecimento: o planejamento de aulas para um curso de graduação presencial. Dissertação de mestrado, Mestrado em Gestão do Conhecimento nas Organizações, Universidade Unicesumar, Maringá, PR, Brasil. 2019.

GERHARDT, T.E.; SILVEIRA, D.T. Métodos de pesquisa. Universidade Aberta do Brasil - UAB/UFRGS Curso de Graduação Tecnológica - Planejamento e Gestão para o Desenvolvimento Rural da SEAD/UFRGS. Porto Alegre: UFRGS, 2009.

GOMES, R. M.; BRITO, E.; VARELA, A. Intervenção na formação no ensino superior: a aprendizagem baseada em problemas (PBL). Interacções, n. 42, p. 44-57, 2016.

HONÓRIO, H. L. G. Sala de aula invertida: uma abordagem colaborativa na aprendizagem de matemática - estudos iniciais. In: EBRAPEM - Encontro Brasileiro de Estudantes de Pós-Graduação em Educação Matemática, 20, 2016, Curitiba, PR. Anais [...]. Curitiba: UFPR, 2016.

MARIN, M. J. S.; LIMA, E. F. G.; MATSUYAMA, D. T.; SILVA, L. K. D.; GONZALES, C.; DEUZIAN, S.; ILIAS, M. Aspectos das fortalezas e fragilidades no uso das metodologias ativas de aprendizagem. Revista Brasileira de Educação Médica, v. 34, n. 1, p. 13-20, 2010.

MORAN, J. M. A educação que desejamos: novos desafios e como chegar lá. 5.ed. Campinas: Papirus, 2015. 
MUNHOZ, A. S. Vamos inverter a sala de aula? 1.ed., Clube de Autores. 2015.

PRADO, M. Pedagogia de projetos: Série Pedagogia de Projetos e Integração de Mídias. Programa Salto para o Futuro, Setembro, 2003.

PRADO, M.E.B.B. Pedagogia de projetos: fundamentos e implicações. In. ALMEIDA, M.E.B; MORAN J.M. (org.) Integração das tecnologias na educação. Brasília: Ministério da Educação - SEED, 2005.

RIBEIRO, E.L.L.; OLIVEIRA, S.F.P. Pedagogia de projetos no ensino interdisciplinar de linguagens e arte: o caso do sarau do curso de letras do UNI-FACEF. Revista Eletrônica de Letras-REL, Franca, SP, v. 10, n. 1, jan./dez. 2017.

RIBEIRO, L. R. C. Aprendizagem baseada em problemas (PBL). São Carlos: EdUFSCar, 2010.

SCHNEIDER, E. I.; SUHR, I. R. F.; ROLON, V. E. K.; ALMEIDA, C. M. Sala de aula invertida em EaD: uma proposta de blended learning. Revista Intersaberes, v. 8, n. 16, jul./dez. 2013.

STRAYER, J. F. The effects of the classroom flip on the learning environment: a comparison of learning activity in a traditional classroom and a flip classroom that used an intelligent tutoring system. 2007. Dissertation (Doctor of Philosophy in the Graduate School). Ohio State University, 2007.

SUHR, I. R. F. Desafios no uso da sala de aula invertida no ensino superior. Revista Transmutare, Curitiba, v. 1, n. 1, p. 4-21, jan./jun. 2016.

VALENTE, J.A; ALMEIDA, M. E. B; GERALDINI, A. F. S. Metodologias ativas: das concepções às práticas em distintos níveis de ensino. Rev. Diálogo Educ., Curitiba, v. 17, n. 52, p. 455-478, abr./jun. 2017. Disponível em:

https://periodicos.pucpr.br/index.php/dialogoeducacional/article/view/9900

VENTURA, M.M. O estudo de caso como modalidade de pesquisa. Pedagogia Médica, Rev SOCERJ, Rio de Janeiro, v. 20, n. 5, p. 383-386, setembro/outubro 2007.

Disponível em: http://encurtador.com.br/cwW39

VENTURELLI, J. Educación médica: nuevos enfoques, metas y métodos. Washington: Organização Panamericana da Saúde, 1997.

VILARINHO, L. R. G. Formação continuada de professores em cursos a distância: lições de três experiências. Rio de Janeiro: Universidade Estácio de Sá, 2004.

UNESCO. Coalizão Global de Educação, 2020. Disponível em:

https://pt.unesco.org/covid19/globaleducationcoalition. Acesso em 25 maio 2020. 